\title{
ARTICLE TYPE \\ Chitosan nanoparticles potentiate the in vitro and in vivo effects of curcumin and other natural compounds
}

\author{
Vanessa Falchetti Lopes ${ }^{1}$, Camila Nascimento Giongo ${ }^{1}$, Laís de Almeida Campos ${ }^{1}$, Wolf-Rainer \\ Abraham $^{2}$, Rubiana Mara Mainardes ${ }^{1}$, Najeh Maissar Khalil ${ }^{1}$ \\ ${ }^{I}$ Pharmaceutical Nanotechnology Laboratory. Universidade Estadual do Centro-Oeste. Alameda Élio Antonio Dalla Vecchia,

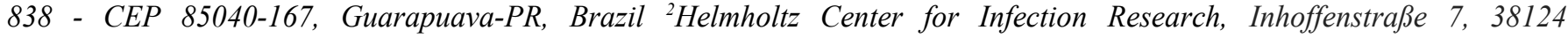 \\ Braunschweig, Germany.
}

\begin{tabular}{l}
\multicolumn{1}{c}{ A R T I C L E H I S T O R Y } \\
\hline Received: \\
Revised: \\
Accepted: \\
DOI:
\end{tabular}

\begin{abstract}
The development of biodegradable nanoparticles is an important tool for the biological transport of chemical compounds. The nanoencapsulation reduces the biopharmaceutical and pharmacokinetic drawbacks of compounds and enhances their biological properties. Naturally occurring polymers such as proteins and polysaccharides have been widely applied in the development of nanostructured systems of several therapeutic agents. Among them is chitosan, a crustacean-carapace-chitin derived biopolymer. In addition to its biocompatibility and biodegradability, chitosan is known for its mucoadhesion properties. Chitosan-based nanostructured systems potentiate most of aspects of the loaded drugs, including cellular transport and other biological effects. The use of chitosan nanoparticles enhances permeation, stability and bioactivity of natural compounds. In this review, an overview of the main features of chitosan nanoparticles that improved in vitro and in vivo effects of bioactive natural molecules is given, emphasizing the results obtained with curcumin.
\end{abstract}

Keywords: chitosan, nanoparticles, curcumin, bioavailability.

\section{INTRODUCTION}

Naturally occurring compounds obtained from several sources, especially plants, have great medical potentials due to their wide variety of chemical structures $[1,2]$. Despite their biological potential, verified in vitro and in vivo assays, these compounds have not achieved meaningful results in pre-clinical or clinical trials [3,4]. This outcome is mainly attributed to the reduction of the solubility and permeability properties of these molecules $[5,6]$.

Curcumin, a natural compound with elevated therapeutic potential and derived from Curcuma sp., has been extensively studied due to its broad spectrum of in vitro effects, such as antioxidant [7], anti-inflammatory [8], and antimicrobial activities [9]. Also, in vivo evaluations have shown anticancer activity $[10,11]$ and protection against neurological [12] and cardiovascular diseases [13].
However, pharmacokinetic restrictions of curcumin limit its therapeutic application [14] due to its pour absorption, fast metabolism and elimination $[15,16,17]$. Pre-clinical studies demonstrate this limitation in rats $[18,19]$ and humans, confirming the limited bioavailability of curcumin on oral application [20, 21].

Nanotechnology arises as an excellent tool for the pharmacokinetic and pharmacodynamic enhancing of natural compounds, optimizing their therapeutic effectiveness and minimizing the problems associated with conventional delivery. [22]. The reduced size of the nanoparticles (NPs) allows not only the improvement of cellular traffic of the drugs, but also provide a sustained release, increasing the drug half-life. The enhancement of drug biodistribution due to its higher absorption leads to the reduction of therapeutic doses and, consequently, the side effects associated to drug use $[23,24,25]$. 
Among the polymers employed for the natural compounds' nanoencapsulation, is chitosan (CS), a natural polymer derived from chitin deacetylation. CS is widely applied in the nanoencapsulation of natural products due to its biocompatibility and biodegradability, required for its application in humans, besides its sustainability. Additionally, its cationic nature favors the adsorption on cell surfaces, which contributes to cell-particle interactions, as well as transport/permeation through cells [26, 27].

This review highlights the main in vitro and in vivo studies of CS nanoparticles loaded with natural compounds, especially curcumin (Cur), over the past 5 years.

\subsection{CHITOSAN NANOPARTICLES: APPLICABILITY AND BENEFITS}

Nanomedicine is the application of nanotechnology for the diagnosis, prevention, and treatment of diseases at cellular and molecular levels. NPs refer to particles that present singular physicochemical properties, emphasizing the reduced size $(<1000 \mathrm{~nm})$ and high proportion between their surface area and volume. These characteristics are exploited to design controlled/sustained release systems based on natural compounds, since they increase the biopharmaceutical, pharmacokinetic and pharmacodynamic properties of the loaded compound [28, 29, 30].

Natural and synthetic polymers are used to guarantee specific targeting and to increase the effectiveness, bioavailability, and stability of the encapsulated compounds [31, 32]. Given the nature of polymeric NPs, it is possible to obtain by different preparation methods, nanospheres, where the compounds are spread or adsorbed on the surface [33], and nanocapsules, in which the compound is trapped in the oil core surrounded by the polymer wall [34].

Several approaches can be employed to obtain NPs, such as solvent emulsification-evaporation, coacervation, nanoprecipitation and ionic gelation [35]. Nevertheless, the choice of the method should consider some important factors, including compound and polymer characteristics, administration route, and application constancy. Furthermore, the NPs must possess biocompatible and biodegradable properties [36].

NPs made of polysaccharides have been extensively developed due to their physical, chemical and biological properties. CS stands out as a biocompatible, biodegradable and non-toxic biopolymer, susceptible to surface modifications aiming to enhance the stability and permeability in the biological system [37, 38, 39].

$\mathrm{CS}$ is a biopolymeric derivative of chitin occurring in crustacean shells. CS forms a linear polycation insoluble in neutral and alkaline aqueous solutions. Differently, in acidic solution, CS shows a high density of positive charges, with hydroxyl and amino groups forming hydrogen bonds, conferring CS the ability to act as a carrier for different therapeutic agents when adsorbing onto negatively charged surfaces. Therefore, CS proved to be an excellent polysaccharide to compose the matrix of nanoparticles [40, 41, 42].

The bioadhesive properties of CS have been demonstrated in several studies [43, 44]. This characteristic stems from the abundance of amino groups in the CS main chain, resulting in increased bioavailability and extended drug release. To enhance the retention, the membrane permeability of charged particles may be facilitated by size and surface binders addition $[45,46]$.

Considering the wide application of $\mathrm{CS}$ in nanostructured systems, some specific characteristics need to be evaluated, for instance, deacetylation degree and molecular mass. An increase on the molecular mass and deacetylation degree leads to elevated reticulation yield, producing larger particles when high CS concentrations are employed [47, 48].

Regarding industrial-scale feasibility, CSpolymer nanostructured systems are promising carriers for drugs such as anticancer, antiinflammatory, and antihistamine compounds, as well as other classes of macromolecules like hormones, proteins, enzymes, and vaccines. In view of this, CS has vast applicability in food, cosmetics, and pharmaceutical industries [49, 50, $51,52]$. 
In addition, CS NPs can also be applied to carry nucleic acids for gene therapy e. g. plasmid DNA. For this, the polyelectrolyte complex technique (PEC) is employed. PEC consists on the addition of a DNA solution to CS dissolved in acetic acid under mechanical stirring, leading to the selfassembly of NPs as a result of the ionic interactions between the cationic polymer and the phosphate groups of the DNA molecule $[53,54]$.

Among the adopted methods for CS-NPs preparation, ionic gelation technique, produced by the ionic interaction between $\mathrm{CS}$ and tripolyphosphate (TPP) (Figure 1), is frequently used. During this process, particle self-assembly occurs due to the interactions between amino and phosphate groups, as well as hydrogen bonds coming from several hydroxyls in the CS chain. As a result, CS cationic polysaccharides create a reticulated structure in the presence of anionic molecules [55]. Therefore, there is a predominance of electrostatic interactions in this structure, so NPs are spontaneously formed under mechanic agitation, which results in small diameter NPs $(200-500 \mathrm{~nm})$ and allows easy reproducibility [56].

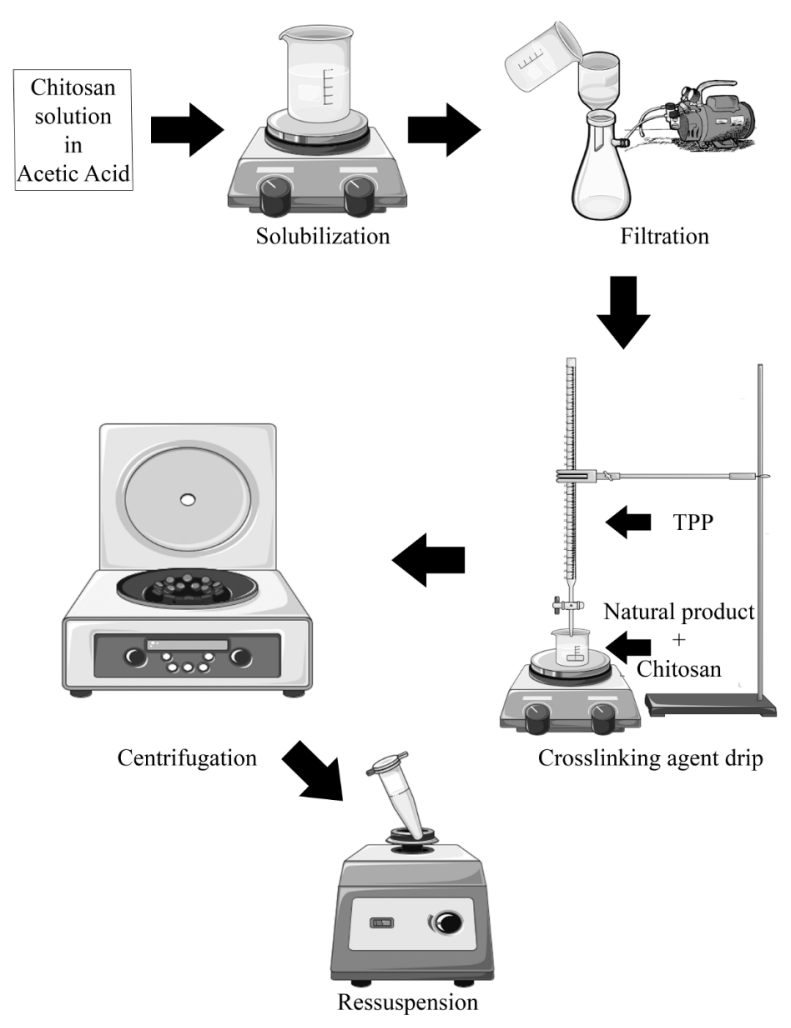

Figure 1: Representative scheme of the ionic gelation process for Chitosan nanoparticles preparation. Images edited using resources made available by LES LABORATORIES SERVIER
Another method described for CS/NPs preparation is the emulsification from organic solvent to isolate particles. However, organic solvents may cause toxicity and are difficult to remove. In the microemulsion method, a surfactant is solubilized into an organic solvent, and then, a solution containing $\mathrm{CS}$ with acetic acid and glutaraldehyde is added to form NPs under mechanic stirring $[57,58,59]$. The CS/NPs can be applied in several administration routes, such as parenteral [60], oral [61], nasal, ocular [62], topical and transdermal [63], increasing the solubility and permeability of different therapeutic agents, ensuring higher bioavailability and maintenance of these compounds in the body [64].

\subsection{CS NANOPARTICLES FOR NATURAL COMPOUNDS DELIVERY}

Phenolic compounds have been used in search for new alternatives for several disease treatments, such as cancer [65], inflammatory [66] and central nervous system illness [67]. Despite attractive results, it is still necessary to overcome delivery and bioavailability limitations of these drugs [68, 69]. In this respect, CS nanoparticles have been used to potentiate their biological activities [70].

Anthocyanins (ACNs) are known for their potential features regarding health. However, these compounds are thermosensitive, with low bioavailability and gastrointestinal stability, which limit their medicinal and food applications [71]. He et al. [72] obtained CS NPs with slow ACNs release in simulated gastrointestinal fluid (GIF), increasing the stability of the encapsulated compound during the storage in a food drink model.

Corroborating these results, CS hydrochloride (CHC) and carboxymethyl CS (CMC) NPs containing ACNs were produced in a study led by Ge et al. [73] with an average size of $178 \mathrm{~nm}$ and encapsulation efficiency of $44 \%$. After storage at $40{ }^{\circ} \mathrm{C}$ for $72 \mathrm{~h}$, the encapsulated compounds presented thermal stability of $88 \%$, while the nonencapsulated compound kept only $10 \%$ of the remnant content. Hence, these results had shown the beneficial characteristics of CS encapsulated ACNs for use in the food industry. Ferulic acid 
(FA) is a natural product with considerable biological properties, but its photosensitivity and low aqueous solubility limit its application as a free drug. El-Marakby et al [74] demonstrated the selective release of FA into HepG2 (hepatocellular carcinoma) cells in its nanostructured CS form modified with glycyrrhizin (GL) during an in vivo study. Besides improving the bioavailability and absorption of FA, the NPs also exhibited higher cytotoxicity to HepG2 cells when compared to the nonencapsulated compound. The authors suggested that GL enabled the internalization of the NPs, mediated via receptors and selective absorption by hepatocytes, along with the passive endocytosis due to the small size of the particles $(<200 \mathrm{~nm})$.

It is important to note that, in this study, AF NPs containing GL reached IC50 of $60 \mu \mathrm{g} / \mathrm{mL}$ on human hepatocellular carcinoma HepG2 cells and were biocompatible to normal cells. These results are promising for clinical studies based on chemotherapeutics.

Another application of FA NPs is as a substitute for methylprednisolone on initial spinal cord injury (SCI) neurodegeneration, since this medicine has shown several side effects and controversial effectiveness [75]. Wu et al [76] developed glycol CS (GC) NPs to encapsulate AF aiming to ascertain their neuroprotector effect against SCI in glutamate-induced cytotoxicity model in mice, since glutamate increase is a pathological indicative of SCI. Compared to the nonencapsulated FA, the NPs presented better effects on neuronal loss and prevented neuritis disintegration. In view of the neuroprotector effect and $98 \%$ neuronal survival obtained with pretreatment using AF NPs, these results have great clinical relevance concerning SCI. Moreover, the NPs demonstrated locomotive function restoration two hours after injury, while the regular methylprednisolone medicine did not lead to any improvement.

Dong et al [77] observed the efficacy of AF CS hydrogel after traumatic brain injury (TBI) in neuronal cells (Neuro -2a) in vitro. As stress after TBI is an important factor for triggering additional brain deficiencies, the inhibition of oxygenreactive species (ORS) prevent secondary brain injuries, indicating the neuroprotective effect of the NPs.

Piperine, present in black pepper, was investigated due to its anticonvulsant action for the treatment of neurological diseases, such as Parkinson and epilepsy [78]. Anissan et al [79] evaluated the in vivo neuroprotector effect of piperine CS NPs through a pentylenetetrazoleinduced epilepsy model. In their study, the NPs reduced cell loss and the astrocytes activation compared to the nonencapsulated compound.

Krill oil $(\mathrm{KO})$ is rich in polyunsaturated fatty acids, has antioxidant properties and is indicated to prevent cardiovascular diseases, but low solubility and oxidative instability of KO limit its biological action [80]. In view of this, CS nanoparticles can represent an alternative to increase utilization of KO. Haider et al [81] developed a CS NPs obtaining 59\% encapsulation efficiency. The NPs prevent $\mathrm{KO}$ oxidation during two weeks of storage.

Scutellaria (SCU), a plant rich in flavonoids, is widely utilized as treatment for cerebral ischemic disease in Chinese medicine. Liu \& Ho [82] developed CS NPs containing SCU for oral and intranasal administration in an adult male C57BL mice model. The verified pharmacokinetic parameters showed increased amounts of SCU in the brain after intranasal administration, indicating the promising application of SCU NPs for sustained release into the brain.

The anticancer action of CS NPs modified with diethylethylamine hydrochloride containing the flavonoid quercetin (QCT) was evaluated in vitro by Pedro et al [83]. The $410 \mathrm{~nm}$ NPs exhibited cytotoxicity effect against breast cancer cells (MCF-7), providing 15\% cellular viability on NPs treat samples, while the samples treated with the nonencapsulated compound showed $50 \%$ cellular viability.

Aluani et al [84] evaluated in vitro and in vivo CS/QCT NPs cytotoxicity effect against HepG2 cells (human and mice hepatocytes). The results indicated lack of cell lysis and the histological, hematological and biochemical samples remained normal, proving the biocompatibility, absence of toxicity and a protector effect of the NPs against HepG2 cells. Baksi et al [85] demonstrated the 
greater antioxidant activity and tumor size reduction in lung and breast cancer (A549 and MDA MB 468 cells) of QCT NPs compared to the nonencapsulated compound, indicating the QCT NPs potential as chemotherapy agent.

The synergic effect obtained with the coencapsulation of QCT and resveratrol (RES) was verified during an in vivo study with rabbits by Natesan et al [86].Because IOP represents a risk factor to glaucoma development and can cause serious eye problems, such as optic neuropathy CS NPs were modified with polyethylene glycol (PEG) for intraocular pressure (IOP) reduction and glaucoma treatment [87]. The results attested better tissue permeation, increase of bioavailability and the prolonged effect of RES on NPs. Also, QCT inclusion increased the RES bioavailability since it competitively inhibits the transmembrane protein P-gp which is associated with multiple drug resistance [88]. The authors attributed these results to CS bioadhesive properties and the PEG role on the action and circulation time improvement of QCT. Also, the nanosystem allowed sustained reduction $(8 \mathrm{~h})$ of IOP, with the highest peak at $4 \mathrm{~h}: 5.5 \pm 0.5 \mathrm{mmHg}$. Therefore, PEG-modified NPs were more effective in RES releasing in comparison, without QCT, the PIO reduction was $48 \pm 0.5 \mathrm{mmHg}$.

Another co-encapsulation study was performed by Ramaswamy et al [89] involving rutin and curcumin. The in vitro results demonstrated sustained release and in vivo studies showed an increase in both compounds bioavailability in relation to the nonencapsulated compounds. According to the authors, this fact can be attributed to the size reduction and surface area increase in NPs, leading to greater permeability and elimination rate decrease.

Hesperidin (Hesp) is a compound with anticancer properties and restricted clinical use due to its low water solubility. Lazer et al [90] synthesized CS NPs conjugated with folic acid to carry Hesp, justifying the folate addition by its ability to mediate the internalization of NPs. The system proved to be seven times more effective in inhibiting colorectal cancer cells (HCT 15) proliferation in relation to the free compound. Besides that, the molecular analysis showed induced apoptosis via pro-apoptotic genes expression.

To increase the solubility and antioxidant effect of Hesp, Cao et al [91] developed CS NPs to carry Hesp using the spray-drying method, which increased about four times Hesp solubility. In addition, the antioxidant activity increased $422 \%$ and $238 \%$ shown by ABTS and DPPH radical scavenger methods, respectively. The results demonstrated an alternative to Hesp applications in food, biomedicine and medicine areas.

Kumar et al [92] prepared naringenin (Na) CS NPs using the ionic gelation method to improve $\mathrm{Na}$ bioavailability after oral administration. The produced NPs showed resistance in SGI, antioxidant activity determined by the DPPH method, and in vitro cytotoxicity over lung cancer cells (A549), as well as the absence of toxicity on normal fibroblasts cells (3T3).

Propolis is widely used since ancient times due to its antioxidant [93], antimicrobial [94], anticancer [95] and wound healing [96] activities. Nevertheless, its low bioavailability and aqueous solubility are significant limitations [97]. In this regard, CS nanoparticles containing propolis have been designed in order to improve the propolis bioactive properties. Ong et al [98] evaluated the antibacterial activity of propolis CS NP against Staphylococcus epidermidis and Enterococcus faecalis. Their results showed biofilm and cellular inhibition by $25 \%$ and $70 \%$, respectively, at the concentration of $100 \mu \mathrm{g} / \mathrm{mL}$ for $S$. epidermidis. For E. faecalis, the CS NP containing propolis extract was even able to inhibit $90 \%$ of bacteria biofilm at the concentration of $100 \mu \mathrm{g} / \mathrm{mL}$.

Elbaz et al [99] explored the anticancer activity of propolis CS NPs with higher solubility and controlled release. The observed cytotoxicity effect on HepG2 cells (human liver cancer) were attributed to apoptosis induction.

Apocynin has been shown therapeutic potential in combating oxidative stress and inflammatory processes, however it has a quick debugging and low bioavailability. Aman, Hashim and Meshali [100] formulated lipidic CS NPs containing apocynin by the emulsification method and observed an increase in oral and intravenous 
bioavailability and in the average residence time compared to the non-encapsulated compound.

Accordingly, CS has proved to be a promising polymer to be used in pharmaceutical nanotechnology for the transport and release of different natural products (Figure 2), showing excellent results related to their absorption, bioavailability, and solubility improvement. Moreover, CS NPs are obtained by simple techniques to enhance the biological and physicochemical properties of various compounds and can be administrated via different routes.

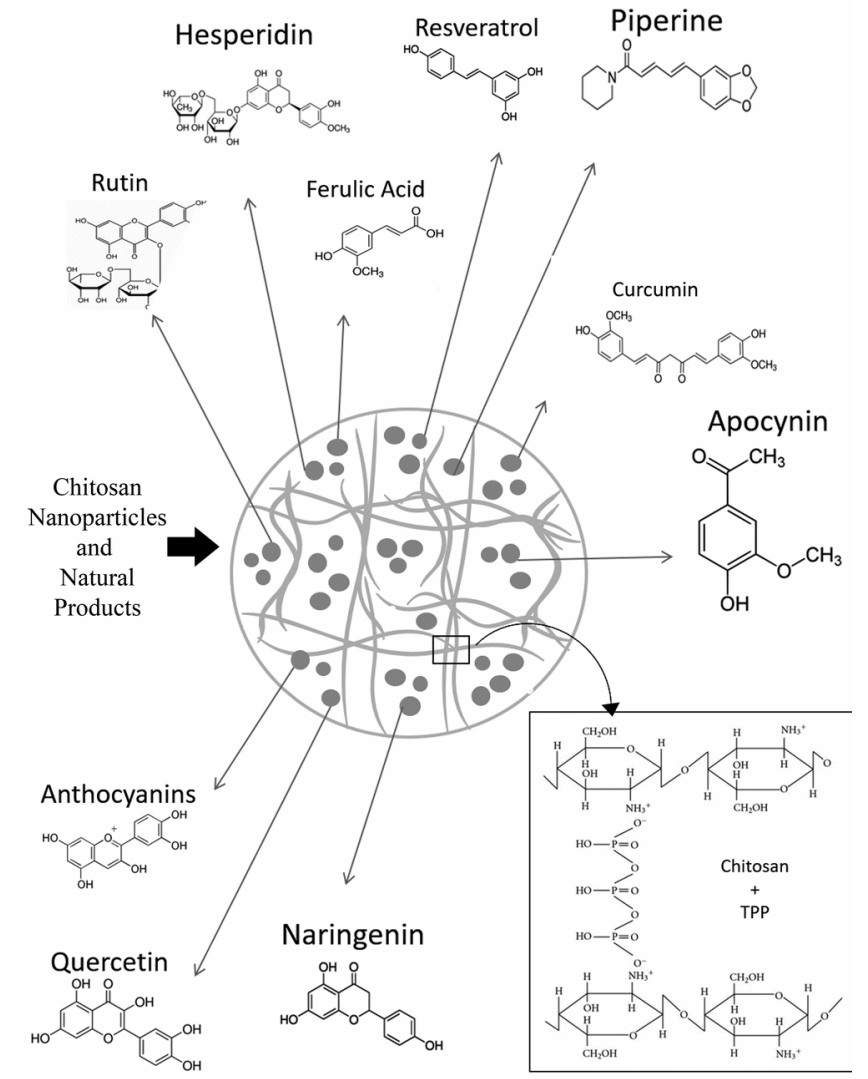

Figure 1: Scheme of chitosan nanoparticles obtained by ionic gelling and representation of loaded natural compounds .

\subsection{CS NANOPARTICLES FOR CURCUMIN DELIVERY}

Cur is one of the most studied natural products for cancer treatment, selected by the U.S. National Cancer Institute as a third-generation chemopreventive agent [101]. Even though there are lots of effort to improve Cur therapeutic effectiveness, Cur is photosensitive and its low solubility, bioavailability, and stability in basic $\mathrm{pH}$ hamper clinical advances with the compound [102].

Chuah et al [103] observed CS NPs containing Cur mucoadhesive effect in an ex vivo study in colorectal cancer cells (HT-29). The Cur NPs displayed stronger internalization compared to the nonencapsulated compound. Chuah et al [104] reported that Cur may interact with the membrane glycoproteins and CS NPs can loosen the cellular occlusive junctions. Also, the positive charged NPs led to high association rate and cellular internalization as a result of their interaction with the negatively charged cellular membranes

Jardim et al [105] designed CS NPs containing Cur using the ionic gelation method and investigated their in vitro cytotoxicity against lung tumors cells (A549). After $72 \mathrm{~h}$, the NPs where inhibited $60 \%$ of the cells, while the nonencapsulated compound inhibition rate was $41 \%$.

Udompornmongkol \& Chiang [106] found similar results for CS NPs containing Cur in the in vitro treatment of rectal colon cancer cells (HT29 and HCT116). The NPs not only demonstrated resistance to GIF, but also showed greater cytotoxicity than the non-encapsulated compound in all tested concentrations. These results were attributed to the higher cell uptake reached due to NPs resistance in the GIF, which permitted the NPs to reach the colon region without significant loses. The promising therapeutic potential of Cur NPs was also demonstrated in vitro against cerebral glioma (C6 cells) [107]. The hyaluronic acid coated CS NPs were able to enter the cells via active endocytosis mediated by the transmembrane glycoprotein CD44, leading to a twofold dose and absorption dependent cytotoxicity in relation to free Cur.

Zheng et al [108] designed CS NPs with Cur to evaluate their cytotoxicity and genotoxicity on renal embryonic cells (HEK 293). The results indicated the safety of NPs, since neither cytotoxic nor genotoxic effects were observed. To evaluate the in vitro apoptotic activity of Cur in different HPV positive cervical cancer cells (SiHa, Hela, Caski, and C33A), Khan et al [109] synthesized 
CS NPs by the emulsion cross-linking technique. Despite the negative cytotoxicity effect on $\mathrm{SiHa}$ cell line, the NPs presented a time and concentration dependent antiproliferative activity against Hela, Caski, and C33A cells. Differently, Fachi et al [110] designed NPs with trimethyl CS (TMC) employing an emulsification-solvent evaporation method to carry $\mathrm{Cur}$, which proved to be resistant to GIF and possessed cytotoxicity to cervical tumor cells ( $\mathrm{SiHa}$ ) and biocompatibility to VERO cells derivative from African green monkey kidney [111].

Abruzzo et al [112] investigated, by means of fluorescence techniques, the internalization of Cur in normal intestinal cell lines (I407) and colorectal cancer cells (HT29), noting no toxicity to I407 cells while HT29 cells were inhibited. These results demonstrated the selective Cur release in cancer cells compared to normal ones.

Duse et al [113] verified Cur CS NPs toxicity against A59 lung cancer cells after $4 \mathrm{~h}$ incubation and subsequent exposure to LED light with $132.1 \mathrm{~J}$ $\mathrm{cm}^{-2}$ using photodynamic therapy (PDT), in which the light excitement of specific photosensitizers produce ORSs, allowing the verification of the cytotoxicity effect with tissue specificity [114] . This result revealed Cur as an efficient photosensitizer, since it led to ORS generation, damaging the tumoral cells and led to cell apoptosis.

Hashemian et al [115] led an in vivo study to evaluate the neuroprotector effect of CS and sodium alginate encapsulated $\mathrm{Cur}$ in a pentylenetetrazole-induced model of chronic epilepsy. The results showed the anticonvulsant activity of NPs and the histologic tests indicated that the NPs reduced the cell death rate and affected neuroglia, confirming the improved neuroprotective property of Cur in its nanoencapsulated form.

Yadav et al [116] performed in vivo and in vitro studies with Cur CS NPs, observing the sustained release of the compound and dose-dependent cytotoxicity activity against HeLa cells. The cellular capture led to DNA damage, cell cycle blockage and high level of ORS generation, followed by cell apoptosis. In addition, tests on zebrafish embryo models showed the absence of toxicity to healthy cells, proving the NPs safety.

Beyond the studies that report CS as the main polymer in NPs formulation, there are also those that use CS as a coating agent. Polycaprolactone (PCL) NPs coated with CS were designed to encapsulate Cur via the nanoprecipitation technique and were evaluated for in vitro treatment of oral cancer. The author confirmed the NPs mucoadhesiveness through permeation studies using esophageal mucosa. Also, antiproliferative effects were observed after $48 \mathrm{~h}$ and the nonencapsulated compound presented greater cytotoxicity effect against oral squamous cell carcinoma (SCC-9) compared to the NPs [117].

Loch-Neckel et al [118] also developed CScoated PCL NPs containing Cur to assess their in vitro cytotoxicity against melanoma cells (B16F10). The results indicated a concentrationdependent reduction in cell viability via apoptosis and a decrease in the expression of metalloproteinases associated with the migration and proliferation of cancer cells. In vivo, the NPs were effective in the reduction of tumor nodules in metastasis of lung cancer cells (C57BL/6).

Cur CS NPs evaluation studies were conducted to improve Cur properties for oral administration, since this compound has low bioavailability and aqueous solubility [119]. Vijayakurup et al [120] led in vivo pharmacokinetic studies with Cur CS NPs, which presented greater cellular uptake and Cur retention comparing to the nonencapsulated form, verifying the sustained release of Cur for $180 \mathrm{~h}$. The NPs also demonstrated pharmacological safety, due to their nontoxic properties and, moreover, were able to reduce tumoral incidence and multiplication in pulmonary adenocarcinoma induced by benzo(a)pyrene.

The slow and sustained release of CS NPs were also observed in the studies conducted by Hasan et al [121], in which the authors evidenced CS NPs potential as Cur carriers, aiming at the oral administration, since the obtained nanosystem allowed $90 \%$ of compound retention on simulated gastrointestinal fluids.

Besides the prolonged and sustained release, the antitumor effectiveness of CS NPs containing Cur was also proven by Elbialy \& Elfatah \& Khalil 
[122]. The in vitro results showed the NPs therapeutic effect against colon (HCT-116) and breast (MCF-7) carcinogenic cells. The morphologic analysis of the cancer cells submitted to NPs demonstrated Cur internalization through cellular aggregates and condensed cytoplasm, confirming the NPs anticancer activity.

Another concerning medical issue is antimicrobial resistance, since the number of available drugs for its treatment has decreased continuously, highlighting the importance of new alternatives for the control of microbial infections [123]. An important effect of antibacterial activity is the synergism between different antimicrobials that can potentiate pathogen inhibition [124].

Among the vast therapeutic properties of Cur, its antibacterial effect stands out. The ORS production promoted by Cur leads to cell death via membrane transport interruption [125] and cell wall and DNA damage [126].

Pseudomonas aeruginosa is an opportunistic microorganism common in immunosuppressed, neutropenic patients or diseases like cystic fibrosis. Furthermore, its adaptive antibiotic resistance mechanisms enable recurrent infections. Therefore, alternative therapies for $P$. aeruginosa infections prevention and treatment are needed [127, 128]. To achieve this, Samrot et al [129] produced CS/Cur NPs smaller than $50 \mathrm{~nm}$, which exhibited in vitro prolonged release and antibacterial activity against $P$. aeruginosa.

Niranjan et al [130] demonstrated the in vitro and in vivo antibacterial activity of CS/Cur NPs on transdermal adhesive. The NPs were tested against Gram-positive and Gram-negative bacteria often found in wounds, such as Bacillus subtilis; Staphylococcus aureus; Escherichia coli and P. aeruginosa, and demonstrated activity against all tested microorganisms. Likewise, the NPs showed biocompatibility to fibroblast cell lines (NIH3T3) and were able to absorb exudate from wounds, reducing microbial colonization and reaching a healing rate higher than the mupirocin treated control group.

Kumar et al [131] also obtained antibacterial CS/Cur NPs and tested them against $S$. aureus, $E$. coli, and $P$. aeruginosa strains, demonstrating NPs activities higher than the commercial drug tetracycline. The NPs promoted the prolonged release of Cur, enabling a connection with the protein receptors on bacteria surface that facilitated the entry into the bacterial cells.

Vishwakarma et al [132] reported a higher in vitro antimicrobial activity of CS/Cur NPs against $E$. coli and $S$. aureus compared to a commercial drug. In their study, vancomycin was effective only against $S$. aureus, while the Cur NPs inhibited both strains in lower concentrations than the nonencapsulated compound. Also, there was not significant difference between NPs and vancomycin on $S$. aureus treatment.

Agel et al (2019) [133] tested the in vitro antibacterial activity of CS/Cur NPs against Staphylococcus saprophyticus and E. coli through PDT. The antibacterial phototoxicity of the CS/Cur NPs was verified through bacterial growth reduction (survival rate lower than $0,1 \%$ in both strains). Additionally, the morphological alterations after PDT onto bacterial structures were observed with electron microscopy.

Barbinta-Petrascu et al [134] developed hybrid folic acid-CS NPs containing Cur and obtained NPs with size of $41 \mathrm{~nm}$ and zeta potential of $-59,5$ $\mathrm{mV}$. The antimicrobial activity was evaluated against $E$. coli and membrane morphological alterations, cytoplasmatic content loss, and consequent apoptosis were observed.

Another study involving hybrid CS NPs was developed by Rao-Kummara et al [135], employing silver and sodium hyaluronate by complexation. This structure inhibited E. coli growth at higher rates compared to $\mathrm{Cur}$ and sodium hyaluronate.

CS/Cur NPs were designed by self-assembly for inhalation aerosol administration of Cur and their antimicrobial activity was evaluated by microdilution in broth. The formulation showed biocompatibility to pulmonary epithelium cells and was effective against Stephanomonas maltophilia and Burkholderia cepacia in a minimum inhibitory concentration (MIC) of 100 $\mu \mathrm{g} / \mathrm{mL}$, and Klebsiella pneumonia and $P$. aeruginosa in MIC of $150 \mu \mathrm{g} / \mathrm{mL}$ [136].

Silver nitrate-CS NPs containing Cur were produced using copolymerization and acrylamine reticulation in CS. The study evaluated the NPs 
antibacterial activity with the method of disc diffusion against $E$. coli and $S$. aureus, verifying bactericidal effect on 99.99\% [137]. CS/Cur NPs with alginate and starch were designed by desolvation, and the antimicrobial activity evaluation was assessed against Streptococcus mutans, achieving an inhibitory effect of $95.28 \%$ [138].

The mentioned works evidenced the importance of the alternative therapy developments regarding bacterial resistance and demonstrated the great potential of CS nanostructures containing Cur both in vitro and in vivo. Another drug carrier types with therapeutic application are CS nanohydrogels. These systems have properties that justify their use for biomedical applications, including biocompatibility, biodegradability and physicochemical improvements of the compounds [139]. According to El-banna et al [140], CS presents hydrogel-based applications potential. It can be employed as gel absorption intensifier, mainly due to its mucoadhesive characteristics that facilitate the permeation into the targeted cells. This way, CS hydrogels have been tested as an alternative for the Cur application in healing processes [1].

Niranjan. et al [130] demonstrated the CS/Cur NPs action on biofilms on epidermal wounds using both in vivo and in vitro methods. The NPs had an average diameter of $20 \mathrm{~nm}$ and presented biocompatibility, injury healing capacity and tissue regeneration superior to the commercial ointment mupirocin. The effect was attributed to the cell proliferation increase, collagen deposition, and antibacterial activity against bacteria found in cutaneous wounds.

Liu et al [141] also designed CS/Cur NPs biofilm and the in vitro and in vivo tests demonstrated Cur sustained release, wounds repairing and greater healing rate compared to the free compound. The biofilm potential is ascribed to their transdermal adhesives that promotes wound healing and tissue regeneration. Rezaii, Oryan \& Javeri [142] tested CS/Cur NPs using an in vivo model of cutaneous wound healing. The authors described the healing via regulation of the expression of the cell growth factor TGF- $\beta 1$ and its antagonist Smad7. In their study, the topic application of CS/Cur NPs provided positive regulation of $\uparrow$ TGF- $\beta 1$ and $\downarrow$ Smad7 factors, resulting in the acceleration of the cellular growth via new blood vessel formation, collagen matrix deposition and therefore, increased epidermis thickness.

Cheng et al [143] designed a CS/Cur nanohydrogel aiming at its topic application for glaucoma treatment. The studies demonstrated that the NPs at concentrations of $20 \mu \mathrm{M}$ did not cause any toxicity and reduced in vitro oxidative stress. The effect was ascribed to apoptosis reduction and inflammation-related genes (TNF; IL-6; IL-1 $\alpha$ ) expression. According to the authors, the oxidative stress provided to the ocular trabecular mesh cells plays an important role in glaucoma pathogenesis, since it compromises the aqueous humor drainage, leading to an eye pressure increase.

CS NPs for Cur delivery proved to be promising, since they improve its solubility, bioavailability and therapeutic effectiveness of the compound. Both in vitro and in vivo results referenced in this review evidence the high potential of CS NPs, which constitute a viable strategy to add value to the widely known and commercialized Cur. Table 1 shows some recently described biological activities of Cur CS NPs. 
Table 1- Chitosan nanoparticles designed for curcumin delivery and main results.

\begin{tabular}{|c|c|c|c|}
\hline $\begin{array}{l}\text { Conducted } \\
\text { Study }\end{array}$ & Assay & Main results & Reference \\
\hline $\begin{array}{l}\text { In vitro, in } \\
\text { vivo and ex } \\
\text { vivo }\end{array}$ & $\begin{array}{c}\text { Gel physicochemical } \\
\text { characterization; permeation } \\
\text { and skin irritability tests }\end{array}$ & $\begin{array}{c}\text { Size: } 84 \mathrm{~nm} \text {; Expressive permeability; } \\
\text { absence of skin irritation; Wound healing } \\
\text { ex vivo }\end{array}$ & {$[144]$} \\
\hline $\begin{array}{l}\text { In vitro and } \\
\text { ex vivo }\end{array}$ & $\begin{array}{c}\text { Physicochemical } \\
\text { characterization and } \\
\text { antitumoral activity against } \\
\text { MCF7 cells (breast cancer) }\end{array}$ & $\begin{array}{l}\text { Size: } 119-127 \mathrm{~nm} ; \mathrm{EE} \%: 96 \% \\
\text { release profile ( } 7 \text { days/ } \mathrm{pH}=5.0): 90 \% \\
\text { cytotoxicity effect greater than the free } \\
\text { compound }\end{array}$ & [145] \\
\hline In vivo & $\begin{array}{c}\text { In vivo oral bioavailability } \\
\text { evaluation and } \\
\text { gastrointestinal release in } \\
\text { vitro (FGS/FIS) of } \\
\text { nanocapsules }\end{array}$ & $\begin{array}{l}\text { Size: } 197 \mathrm{~nm} ; \mathrm{EE} \%: 92 \% \text {; } \\
\text { greater bioavailability compared to the free } \\
\text { Cur; Low resistance to SGF/SIF }\end{array}$ & [102] \\
\hline In vivo & $\begin{array}{l}\text { Antioxidant activity against } \\
\text { cadmium induced oxidative } \\
\text { stress }\end{array}$ & $\begin{array}{l}\text { Antioxidant action due to inhibited toxicity } \\
\text { by cadmium and enzymatic index increase } \\
\text { (catalase and superoxide dismutase) }\end{array}$ & [146] \\
\hline In vivo & $\begin{array}{l}\text { Cytotoxicity activity against } \\
\text { cervical tumoral cells }\end{array}$ & $\begin{array}{l}\text { Increase of cell capture and antitumoral } \\
\text { activity against } \mathrm{SiHa}, \mathrm{CaSKi} \text { and HeLa }\end{array}$ & {$[147]$} \\
\hline In vivo & $\begin{array}{l}\text { Antifungal activity against } \\
\text { Candida albicans }\end{array}$ & $\begin{array}{l}\text { Stronger anti-Candida albicans effect than } \\
\text { chlorhexidine; mouth ulcer decrease and } \\
\text { better healing compared to benzidamine }\end{array}$ & [148] \\
\hline In vivo & $\begin{array}{l}\text { Cytotoxicity effect against } \\
\text { lung cancer (H1299 cells) in } \\
\text { animal model induced by } \\
\text { benzopyrene }\end{array}$ & $\begin{array}{c}\text { Size: } 170-200 \mathrm{~nm} \text {; Sustained release; } \\
\text { increase of bioavailability; expressive cell } \\
\text { capture; } \\
\text { greater reduction of H1299 cells viability }\end{array}$ & [120] \\
\hline
\end{tabular}




\begin{tabular}{|c|c|c|c|}
\hline & & compared to free Cur & \\
\hline In vivo & $\begin{array}{l}\text { Healing and cytotoxicity } \\
\text { activity evaluation on human } \\
\text { keratinocytes cells (HaCaT) }\end{array}$ & $\begin{array}{l}\text { Size: } 140 \mathrm{~nm} ; \mathrm{EE} \%: 78 \% \text {; } \\
\text { high healing activity (closing > than 90\%); } \\
\text { absence of cytotoxicity over keratinocytes }\end{array}$ & [149] \\
\hline In vitro & $\begin{array}{l}\text { Transdermal permeability and } \\
\text { cytotoxicity tests on human } \\
\text { keratinocytes cells (HaCaT) }\end{array}$ & $\begin{array}{c}\text { Size: } 167-251 \mathrm{~nm} ; \mathrm{EE} \%: 80 \% \\
\text { greater transdermal permeation and } \\
\text { cellular viability than free compound }\end{array}$ & {$[150]$} \\
\hline In vivo & $\begin{array}{l}\text { Cytotoxicity assays in breast } \\
\text { cancer cells (MCF-7) }\end{array}$ & $\begin{array}{c}\text { Size: } 130 \mathrm{~nm} ; \mathrm{EE} \%: 87.5 \% \\
\text { cytotoxicity in MCF-7 cells: NPs }(70 \%) \\
\text { free Cur }(71.6 \%)\end{array}$ & [151] \\
\hline
\end{tabular}

\section{CONCLUDING REMARKS}

Concerning the biological properties of natural compounds, several studies have reported the design of nanoparticles, especially the ones containing chitosan, to improve their delivery and targeting, aiming to circumvent the biological barriers and enhance compound absorption and bioavailability, thereby potentiating their therapeutic effect.

The high potential of natural compounds on prevention and treatment of age-related diseases and cancer is evident. However, their potentiality is suppressed in conventional delivery and dosage forms. Low solubility and cellular permeability, as well as chemical instability of the natural compounds negatively modulate the biopharmaceutical phase. As a consequence, the pharmacokinetic parameters are often poor, evidencing low bioavailability and short half-life, hindering the in vivo therapeutic efficacy. Here, the nanoencapsulation represents an important tool for effectively exploiting the potential of natural compounds.
This review gathered encouraging results of CS NPs for the nanoencapsulation of natural compounds. The described works embraced improvements on drug solubility, permeability, stability, bioavailability, biodistribution, and longlasting residence in the body. The differentiated intracellular traffic of drug-loaded CS NPs compared to free drug explains the NPs potentiation of the recognized biological effects of natural compounds and represents a new pathway for the pharmaceutical industry.

More research is needed on the pharmacokinetics of drug release from CS NPs under different conditions and in different organs, on the synergetic effects of drugs incapsulated in NPs or the specificities of CS NPs on cancer cells. However, high expectations for clinical applications are justified from what we already know from the reports of chitosan nanoparticles loaded with various drugs.

\section{CONSENT FOR PUBLICATION}

\section{CONFLICT OF INTEREST}

The authors declare no conflict of interest.

\section{ACKNOWLEDGMENTS}

The authors would like to thank CAPES for the scholarship given to L. de A. Campos (88882.464225/2019-01).

\section{REFERENCES}

[1] Pham, J. V.; Yilma, M. A., Feliz, A.; Majid, M. T.; Maffetone, N.; Walker, J. R.; Kim, E.; Cho, H. J.; Reynolds, J. M.; Song, M. C.; Park, S. R.; Yoon, Y. J. A review of the 
microbial production of bioactive natural products and biologics. Front. Microbiol, 2019, 10 (1404).

[2] Gorzynik-Debicka, M., Przychodzen, P., Cappello, F., Kuban-Jankowska, A.; Marino-Gammazza, A.; Knap, N.; Wozniak, M.; Gorska-Ponikowska, M. Potential health benefits of olive oil and plant polyphenols. Int. J. Mol. Sci, 2018, 19 (3), 686.

[3] Daliu, P.; Santini, A.; Novellino, E. From pharmaceuticals to nutraceuticals: bridging disease prevention and management. Expert. Rev. Clin. Pharmacol, 2019, 12 (1), 1-7.

[4] Adiwidjaja, J.; Mclachlan, A. J.; Boddy, A. V. Curcumin as a clinically-promising anti-cancer agent: pharmacokinetics and drug interactions. Expert. Opin. Drug. Metab. Toxicol, 2017, 13 (9), 953-972.

[5] Bilia, A. R.; Piazzini, V.; Guccione, C.; Risaliti, L.; Asprea, M.; Capecchi, G.; Bergonzi, M. C. Improving on nature: the role of nanomedicine in the development of clinical natural drugs. Planta Med, 2017, 83 (5), 366-381.

[6] Varsha, K.; Sharma, A.; Kaur, A.; Madan, J.; Pandey, R. S.; Jain, U. K.; Chandra, R. Natural plant-derived anticancer drugs nanotherapeutics: a review on preclinical to clinical success. Micro. Nano. Tech, 2017, 775-809.

[7] Leiva-Veja, J.; Villalobos-Carvajal, R.; Ferrari, G.; Donsi, F.; Zuniga, R. N.; Shene, C.; Beldarraín-Iznaga. Influence of interfacial structure on physical stability and antioxidante activity of curcumin multilayer emulsions. Food Bioproducts Processing, 2020, 121, 65-75.

[8] Kong, Z. L.; Sudirman, S.; Lin, H. J.; Chen, W. N. In vitro anti-inflammatory effects of curcumin on mast cellmediated allergic responses via inhibiting FceRI protein expression and protein kinase $\mathrm{C}$ delta translocation. Cytotechnology, 2020, 72 (1), 81-95.

[9] Noorafshan, A., Ashkani-Esfahani, S. A Review of therapeutic effects of curcumin. Curr. Pharm. Des, 2013, 19 (11), 2032-46.

[10] Thornthwaite, J. T., Shah, H. R., England, S. R., Roland, L. H.; Thibado, S. P.; Ballard, T. K.; Goodman, B. T. Anticancer effects of curcumin, artemisinin, genistein, and resveratrol, and vitamin C: Free versus liposomal forms. Adv. Biol. Chem, 2017, 7, 27-41.

[11] Zhao, S., Pi, C., Ye, Y., Zhao, L.; Wei, Y. Recent Advances of analogues of curcumin for treatment of cancer. Eur. J. Med. Chem, 2019, 180, 524-535.
[12] Dong, W., Yang, B., Wang, L., Li, B.; Guo, X.; Zhang, M.; Jiang, Z.; Fu, J.; Pi, J.; Guan, D.; Zhao, R. Curcumin plays neuroprotective roles against traumatic brain injury partly via NRF2 signaling. Toxicol. Appl. Pharmacol, 2018, 346, 28-36.

[13] Li, X., Xiao, H., Lin, C.; Weitong, S.; Teng, W.; Jin, W.; Bin, C.; Xia, C.; Du, C. Synergistic effects of liposomes encapsulating atorvastatin calcium and curcumin and targeting dysfunctional endothelial cells in reducing atherosclerosis. Int. J. Nanomed, 2019, 14, 649-665.

[14] Kakkar, V.; Kumari, P.; Adlakha, S.; Kaur, I. P. Curcumin and its nanoformulations as therapeutic for Alzheimer's disease. Nanobiotech. Neur. Dis, 2019, 343367.

[15] Liu, W.; Zhai, Y.; Heng, X.; Che, F. Y.; Chen, W.; Sun, D.; Zhai, G. Oral bioavailability of curcumin: Problems and advancements. J Drug Target, 2016, 24, 694-702.

[16] Lopresti, A. L. The problem of curcumin and its bioavailability: Could its gastrointestinal influence contribute to its overall health-enhancing effects? Adv Nutr, 2018, 9, 41-50.

[17] Antunes, A. H.; Faria, F. R.; Mota, J. F.; Santiago, M. F.; Kogawa, A. C.; Rezende, K. R. Bioanalytical method by HPLC-FLD for curcumin analysis in supplemented athletes. Saudi Pharm J, 2020, 28, 599-606.

[18] Boyanapalli, S. S. S.; Huang, Y.; Su, Z.; Cheng, D.; Zhang, C.; Guo, Y.; Rao, R.; Andoulakis, I. P.; Kong, A. N. Pharmacokinetics and pharmacodynamics of curcumin in regulating anti-inflammatory and epigenetic gene expression. Biopharm Drug Dispos, 2018, 39, 289-297.

[19] Wang, L.; Li, W.; Cheng, D.; Guo, Y.; Wu, R.; Yin, R.; Li, S.; Kuo, H. C.; Hudlikar, R.; Yang, H.; Buckley, B.; Kong, A. N. Pharmacokinetics and pharmacodynamics of three oral formulations of curcumin in rats. $J$ Pharmacokinetics and Pharmacodynamics, 2020, 47, 131144.

[20] Stohs, S. J.; Ji, J.; Bucci, L. R.; Preuss, H. G. A Comparative pharmacokinetic assessment of a novel highly bioavailable curcumin formulation with 95\% curcumin: A randomized, double-blind, crossover study. J Am Coll Nutr, 2018, 37, 51-59.

[21] Cheng, D.; Li, Q.; Wang, L.; Lin, T.; Poiani, G.; Wassef, A.; Hudlikar, R.; Ondar, P.; Brunetti, L.; Kong, A. N. Pharmacokinetics, pharmacodynamics, and PKPD modeling of curcumin in regulating antioxidant and 
epigenetic gene expression in healthy human volunteers. $\mathrm{Mol}$ Pharm, 2019, 16, 1881-1889.

[22] Siddiqui, I. A.; Adhami, V. M.; Bharali, D. J.; Hafeez, B. B.; Asim, M.; Khwaja, S. I.; Ahmad, N.; Cui, H.; Mousa, S. A.; Mukhtar, H. Introducing nanochemoprevention as a novel approach for cancer control: proof of principle with green tea polyphenol epigallocatechin-3-gallate. Cancer. Res, 2009, 69 (5), 1712-1716.

[23] Fattahian-Kalhor, N.; Saeidifar, M.; Ramshini, H.; Saboury, A. A. Interaction, cytotoxicity and sustained release assessment of a novel antitumor agent using bovine serum albumin nanocarrier. J. Biomol. Struct. Dyn, 2019, 9, $1-13$.

[24] Rajendran, R.; Radhai, R.; Kotresh, T. M.; Csiszar, E. Development of antimicrobial cotton fabrics using herb loaded nanoparticles. Carbohydr. Polym, 2013, 91 (2), 613617.

[25] Qureshi, O. S.; Kim, H. S.; Zeb, A.; Choi, J. S.; Kim, H. S.; Kwon, J. E.; Kim, M. S.; Kang, J. H.; Ryou, C.; Park, J. S.; Kim, J. K. Sustained release docetaxel incorporated lipid nanoparticles with improved pharmacokinetics for oral and parenteral administration. J. Microencapsul, 2017, 34 (3), $250-261$

[26] Rozman, N. A. S.; Tong, W. Y.; Leong, C. R.; Tan, W. N.; Hasanolbasori, M. A.; Abdullah, S. Z. Potential antimicrobial applications of chitosan nanoparticles (CHNP). J. Microbiol. Biotechnol, 2019, 29 (7), 1009-1013.

[27] Mohammed, M. A.; Syeda, J. T. M.; Wasan, K. M.; Wasan, E. K. An overview of chitosan nanoparticles and its application in non-parenteral drug delivery. Pharmaceutics, 2017, 9 (4), 53.

[28] Anand, A., Sugumaran, A., Narayanasamy, D. Brain targeted delivery of anticancer drugs: prospective approach using solid lipid nanoparticles. IET Nanobiotechnol, 2019, 13 (4), 353-362.

[29] Banerjee, A.; Qi, J.; Gogoi, R.; Wong, J.; Mitragotri, S. Role of nanoparticle size, shape and surface chemistry in oral drug delivery. J. Control. Release, 2016, 238, 176-185.

[30] Kumari, A., Yadav, S. K., Yadav, S. C. Biodegradable polymeric nanoparticles based drug delivery systems. Colloids. Surf B. Biointerfaces, 2010, 75 (1), 1-18.

[31] Gao, Y., Xie, J., Chen, H. Nanotechnology-based intelligent drug design for cancer metastasis treatment. Biotechnol. Adv, 2014, 32 (4), 761-77.

[32] Wicki, A.; Witzigmann, D.; Balasubramanian, V.; Huwyler, J. Nanomedicine in cancer therapy: challenges, opportunities, and clinical applications. J. Control. Release, 2015, 200, 138-57.

[33] Soppimath, K. S.; Aminabhavi, T. M.; Kulkarni, A. R.; Rudzinski, W. E. Biodegradable polymeric nanoparticles as drug delivery devices. J. Control. Release, 2001, 70, 1-20.

[34] Erdogar, N., Akkin, S., Bilensoy, E. Nanocapsules for drug delivery: an updated review of the last decade. Recent. Pat. Drug. Deliv. Formul, 2018, 12 (4), 252-266.

[35] Quintanar-Guerrero, D.; Allémann, E.; Fessi, H.; Doelker, E. Preparation techniques and mechanisms of formation of biodegradable nanoparticles from preformed polymers. Drug. Dev. Ind. Pharm, 1998, 24 (12), 1113-1128.

[36] Chandra-Hembram, K.; Prabha, S.; Chandra, R.; Ahmed, B.; Nimesh, S. Advances in preparation and characterization of chitosan nanoparticles for therapeutics. Artif. Cells. Nanomed. Biotechnol, 2016, 44 (1), 305-314.

[37] Shariatinia, Z. Pharmaceutical applications of chitosan. Adv. Colloid. Interface. Sci, 2019, 263, 131-194.

[38] Dong, C., Chen, W., Liu, C. Flocculation of algal cells by amphoteric chitosan-based flocculant. Bioresour Technol, 2014, 170, 239-247.

[39] Elgadir, M. A.; Uddin, M. S.; Ferdosh, S.; Adam, A.; Chowdhury, A. J. K.; Sarker, M. Z. I. Impact of chitosan composites and chitosan nanoparticle composites on various drug delivery systems: a review. J. Food. Drug. Anal, 2015, 23 (4), 619-629.

[40] Wang, J. J.; Zeng, Z. W.; Xiao, R. Z.; Xie, T.; Zhou, G. L.; Zhan, X. R.; Wang, S. L. Recent advances of chitosan nanoparticles as drug carriers. Int. J. Nanomed, 2011, 6, 765774.

[41] Prabaharan, M. Chitosan-based nanoparticles for tumortargeted drug delivery. Int. J. Biol. Macromol, 2015, 72, 1313-1322.

[42] Kumar, K.; Dhawan, N.; Sharma, H.; Vaidya, S.; Vaidya, B. Bioadhesive polymers: Novel tool for drug delivery. Artif. Cells. Nanomed. Biotechnol, 2014, 42 (4), 274-283.

[43] Dou, T.; Wang, J.; Han, C.; Shao, X.; Zhang, J.; Lu. W. Cellular uptake and transport characteristics of chitosan modified nanoparticles in Caco-2 cell monolayers. Int J Biol Macromol, 2019, 138, 791-799.

[44] Cordenonsi, L. M.; Faccendini, A.; Catanzaro, M.; Bonferoni, M. C.; Rossi, S.; Malavasi, L.; Raffin, R. P.; Schapoval, E. E. S.; Lanni, C.; Sandri, G.; Ferrari, F. The role of chitosan as coating material for nanostructured lipid carriers for skin delivery of fucoxanthin. Int $J$ Pharm, 2019, $567,118487$. 
[45] Rathananand, M.; Kumar, D. S.; Shirwaikar, A.; Kumar, R.; Sampath-Kumar, D.; Prasad, R. S. Preparation of mucoadhesive microspheres for nasal delivery by spray drying. Ind. J. Pharm. Sci, 2007, 69 (5), 651.

[46] He, P., Davis, S. S., Illum, L. In vitro evaluation of the mucoadhesive properties of chitosan microspheres. Int. J. Pharm, 1998, 166, 75-88.

[47] Bao, H.; Li, L.; Zhang, H. Influence of cetyltrimethylammonium bromide on physicochemical properties and microstructures of chitosan TPP nanoparticles in a aqueous solutions. J. Colloid. Inter. Sci, 2008, 328 (2), 270-27.

[48] Quiñones, J. P.; Peniche, H.; Peniche, C. Chitosan based self-assembled nanoparticles in drug delivery. Polymers, 2018, 10, 235-267.

[49] Croisier, F.; Jérôme, C. Chitosan-based biomaterials for tissue engineering. Eur. Poly. J, 2013, 49 (4), 780-792.

[50] Almalik, A.; Day, P. J.; Tirelli, N. Ha-coated chitosan nanoparticles for CD44-mediated nucleic acid delivery. Macromol. Biosci, 2013, 13 (12), 1671-1680.

[51] Jain, A.; Thakur, K.; Kush, P.; Jain, U. K. Docetaxel loaded chitosan nanoparticles: formulation, characterization and cytotoxicity studies. Int. J. Biol. Macromol, 2014, 69, 546-553.

[52] Bugnicourt, L.; Ladavière, C. Interests of chitosan nanoparticles ionically cross-linked with tripolyphosphate for biomedical applications. Prog. Poly. Sci, 2016, 60, 1-17.

[53] Erbacher, P.; Zou, S.; Bettinger, T.; Steffan, A. M.; Remy, J. S. Chitosan-based vector/DNA complexes for gene delivery: biophysical characteristics and transfection ability. Pharm. Res, 1998, 15, 1332-1339.

[54] Jayakumar, R.; Chennazhi, K. P.; Muzzarelli, R. A. A.; Tamura, H.; Nair, S. V.; Selvamurugan, N. Chitosan conjudated DNA nanoparticles in gene therapy. Carb. Polym, 2010, 79 (1), 1-8.

[55] Neves, A. L. P.; Milioli, C. C.; Müller, L.; Riella, H. G.; Kuhnen, N. C.; Stulzer, H. K. Factorial design as tool in chitosan nanoparticles development by ionic gelation technique. Col. Surf. A: Physicochem. Eng. Asp, 2014, 445, 34-39.

[56] Anirudhan, T. S.; Divya, P. L.; Nima, J. Synthesis and characterization of novel drug delivery system using modified chitosan based hydrogel grafted with cyclodextrin. Chem. Eng. J, 2016, 284, 1259-1269.
[57] Niwa, T.; Takeuchi, H.; Hino, T.; Kunou, N.; Kawashima, Y. Preparations of biodegradable nanospheres of water-soluble and insoluble drugs with D, L-lactide/glycolide copolymer by a novel spontaneous emulsification solvent diffusion method, and the drug release behavior. J. Control. Release, 1993, 25, (1-2), 89-98.

[58] Maitra, A.; Ghosh, P. K.; De, T. K.; Sahoo, S. K. Process for the preparation of highly monodispersed hydrophilicpolymeric nanoparticles of size less than $100 \mathrm{~nm}$. US patent, 1999, 5874,111.

[59] El-Shabouri, M. H. Positively charged nanoparticles for improving the oral bioavailability of cyclosporin-A. Int. J. Phar, 2002, 249, (1-2), 101-108.

[60] Kefayat, A.; Vaezifar, S. Biodegradable PLGA implants containing doxorubicin-loaded chitosan nanoparticles for treatment of breast tumor-bearing mice. Int. J. Macromol, 2019, 136, 48-56.

[61] Demirbolat, G. M.; Altintas, L.; Yilmaz, S.; Degim, I. T.; Development of orally applicable, combinatorial drugloaded nanoparticles for the treatment of fibrosarcoma. $J$. Pharm. Sci, 2018, 107 (5), 1398-1407.

[62] Silva, N. C.; Silva, S.; Sarmento, B.; Pintado, M. Chitosan nanoparticles for daptomycin delivery in ocular treatment of bacterial endophthalmitis. Drug. Deliv, 2015, 22 (7), 885-893

[63] Keyal, U.; Luo, Q.; Bhatta, A. K.; Luan, H.; Zhang, P.; Wu, Q.; Zhang, H.; Liu, P.; Zhang, L.; Wang, P.; Yang, D.; Zhang, G.; Yao, J.; Wang, X.; Shi, L. Zinc pthalocyanineloaded chitosan/m PEG-PLA nanoparticles-mediated photodynamic therapy for the treatment of cutaneous squamous cell carcinoma. J. Biophotonics, 2018, 11 (11), 2018.

[64] Ahmed, T. A.; Aljaeid, B. M. Preparation, characterization, and potential application of chitosan, chitosan derivatives, and chitosan metal nanoparticles in pharmaceutical drug delivery. Drug. Des. Devel. Ther, 2016 , $10,483-507$.

[65] Muller, A. G.; Sarker, S. D.; Saleem, I. Y.; Hutcheon, G. A. Delivery of natural phenolic compounds for the potential treatment of lung cancer. Daru, 2019, 27, 433-449.

[66] Brezani, V.; Smejkal, K.; Hosek, J.; Tomasova, V. Antiinflammatory Natural prenylated phenolic compounds Potential lead substances. Curr Med Chem, 2018, 25, 10941159.

[67] Yavarpour-Bali, H.; Ghasemi-Kasman, M.; Pirzadeh, M. Curcumin-loaded nanoparticles: A novel therapeutic strategy in treatment of central nervous system disorders. Int J Nanomedicine, 2019, 14, 4449-4460.

[68] Patel, S. S.; Acharya, S.; Ray, R. S.; Agrawal, R.; Raghuwanski, R.; Jain, P. Cellular and molecular 
mechanisms of curcumin in prevention and treatment of disease. Crit Rev Food Sci Nutr, 2020, 60, 887-939.

[69] Perrone, L.; Sampaolo, S.; Melone, M. A. B. Bioactive phenolic compounds in the modulation of central and peripheral nervous system cancers: Facts and misdeeds. Cancers (Basel), 2020, 12, 454.

[70] Puertas-Bartolomé, M.; Benito-Garzón, L.; Fung, S.; Kohn, J.; Vázquez-Lasa, B.; Román, J. S. Bioadhesive functional hydrogels: Controlled release of catechol species with antioxidant and antiinflammatory behavior. Mater Sci Eng C Mater Biol Appl, 2019, 105, 110040.

[71] Kalt, W.; Mcdonald, J. E.; Vinqvist-Tymchuk, M. R; Liu, Y.; Fillmore, S. A. E. Human anthocyanin bioavailability: effect to intake duration and dosing. Food \& Function, 2017, 8 (12), 4563-4569.

[72] He, B.; Ge, J.; Yue, P.; Yue, X.; Fu, R.; Liang, J.; Gao, $\mathrm{X}$. Loading of anthocyanins on chitosan nanoparticles influences anthocyanin degradation in gastrointestinal fluids and stability in a beverage. Food. Chem, 2017, 221, 16711677.

[73] Ge, J.; Yue, P.; Chi, J.; Liang, J.; Gao, X. Formation and stability of anthocyanins-loaded nanocomplexes prepared with chitosan hydrochloride and carboxymethyl chitosan. Food. Hydro, 2018, 74, 23-31.

[74] El-Marakby, E. M.; Hathout, R. M.; Taha, I.; Mansour, S.; Mortada, N. D. A novel serum-stable liver targeted cytotoxic system using valerate-conjugated chitosan nanoparticles surface decorated with glycyrrhizin. Int. J. Pharm, 2017, 525 (1), 123-138.

[75] Tsutsumi, S.; Ueta, T.; Shiba, K.; Yamamoto, S.; Takagishi, K. Effects of the second national acute spinal cord injury of high-dose methylprednisolone therapy on acute cervical spinal cord injury-results in Spinal Injuries Center. Spine, 2006, 31 (26), 2992-2996.

[76] Wu, W.; Lee, S. Y.; Wu, X.; Tyler, J. Y.; Wang, H.; Ouyang, Z.; Park, K.; Xu, X. M.; Cheng, J. X. Neuroprotective ferulic acid (FA)-Glycol Chitosan (GC) nanoparticles for functional restoration of traumatically injured spinal cord. Biomaterials, 2014, 35 (7), 2355-2364.

[77] Dong, G. C.; Kuan, C. Y.; Subramaniam, S.; Zhao, J. Y.; Sivasubramaniam, S.; Chang, H. Y.; Lin, F. H. A potent inhibition of oxidative stress induced gene expression in neural cells by sustained ferulic acid release from chitosan based hydrogel. Mater. Sci. Eng. C. Mater. Biol. Appl, 2015, 49, 691-699.

[78] Correia, A. O.; Cruz, A. A. P.; Aquino, A. T. R.; Diniz, J. R. G.; Santana, K. B. F.; Cidade, P. I. M.; Peixoto, J. D.;
Lucetti, D. L.; Nobre, M. E. P.; Cruz, G. M. P.; Neves, K. R. T.; Viana, G. S. B. Neuroprotective effects of piperine, an alkaloid from the Piper genus, on the Parkinson's disease model in rats. $J$. Neurol. Therap, 2015, 1 (1), 1-8.

[79] Anissian, D.; Ghasemi-Kasman, M.; Khalili-Fomeshi, M.; Akbari, A.; Hashemian, M; Kazemi, S.; Moghadamnia, A. A. Piperine-loaded chitosan-STPP nanoparticles reduce neuronal loss and astrocytes activation in chemical kindling model of epilepsy. Int. J. Biol. Macromol, 2018, 107, 973983.

[80] Tur, J. A.; Bibiloni, M. M.; Sureda, A.; Pons, A. Dietary sources of omega 3 fatty acids: public health risks and benefits. Br. J. Nutr, 2012, 107, 23-52.

[81] Haider, J.; Majeed, H.; Williams, P. A.; Safdar, W.; Zhong, F. Formation of chitosan nanoparticles to encapsulate krill oil (Euphausia superba) for application as a dietary supplement. Food. Hydrocol, 2017, 63, 27-34.

[82] Liu, S.; Ho, P. C. Intranasal administration of braintargeted HP- $\beta-\mathrm{CD} / \mathrm{Chitosan}$ nanoparticles for delivery of scutellarin, a compound with protective effect in cerebral ischaemia. J. Pharm. Pharmacol, 2017, 69 (11), 1495-1501.

[83] Pedro, R. O.; Goycoolea, F. M.; Pereira, S.; Schmitt, C. C.; Neumann, M. G. Synergistic effect of quercetin and $\mathrm{pH}-$ responsive DEAE-chitosan carriers as drug delivery system for breast cancer treatment. Int. J. Biol. Macromol, 2018, 106, 579-586.

[84] Aluani, D.; Tzankova, V.; Kondeva-Burdina, M.; Yordanov, Y.; Nikolova, E.; Odzhakov, F.; Apostolov, A.; Markova, T.; Yoncheva, K. Evaluation of biocompatibility and antioxidante efficiency of chitosan-alginate nanoparticles loaded with quercetin. Int. J. Biol. Macromol, 2017, 103, 771-782.

[85] Baksi, R.; Singh, D. P.; Borse, S. P.; Rana, R.; Sharma, V.; Nivsarkar, M. In vitro and in vivo anticancer efficacy potential of quercetin loaded polymeric nanoparticles. Biomed. Pharmacotherapy, 2018, 106, 1513-1526.

[86] Natesan, S.; Pandian, S.; Ponnusamy, C.; Palanichamy, R.; Muthusamy, S.; Kandasamy, R. Co-encapsulated resveratrol and quercetin in chitosan and peg modified chitosan nanoparticles: for efficient intra ocular pressure reduction. Int. J. Biol. Macromol, 2017, 104, 1837-1845.

[87] Susanna, R.; De-Moraes, C. G.; Cioffi, G. A.; Ritch, R. Why do people (still) go blind from glaucoma? Transl. Vis. Sci. Technol, 2015, 4 (2).

[88] Abdallah, H. M.; Al-Abd, A. M.; El-Dine, R. S.; ElHalawany, A. M. P-glycoprotein inhibitors of natural origin as potential tumor chemosensitizers: a review. $J$. Adv. Res, 2015, 6 (1), 45-62. 
[89] Ramaswamy, S.; Dwarampudi, L. P.; Kadiyala, M.; Kuppuswamy, G.; Veera, V. S. R. K.; Kumar, C. K. A.; Paranjothy, M. Formulation and characterization of chitosan encapsulated phytoconstituents of curcumin and rutin nanoparticles. Int. J. Biol. Macromol, 2017, 104, 1807-1812.

[90] Mary-Lazer, L.; Sadhasivam, B.; Palaniyandi, K.; Muthuswamy, T.; Ramachandran, I.; Balakrishnan, A.; Pathak, S.; Narayan, S.; Ramalingam, S. Chitosan-based nano-formulation enhances the anticancer efficacy of hesperetin. Int. J. Biol. Macromol, 2018, 107, 1988-1998.

[91] Cao, R.; Zhao, Y.; Zhou, Z.; ZHAO, X. Enhancement of the water solubility and antioxidante activity of hesperidin by chitooligosaccharide. J. Sci. Food. Agric, 2018, 98 (6), 2422-2427.

[92] Kumar, S. P.; Birundha, K.; Kaveri, K.; Devi, K. T. R. Antioxidant studies of chitosan nanoparticles containing naringenin and their cytotoxicity effects in lung cancer cells. Int. J. Biol. Macromol, 2015, 78, 87-95.

[93] Guimarães, N. S. S.; Mello, J. C.; Paiva, J. S.; Bueno, P. C. P.; Berreta, A. A.; Torquato, R. J.; Nantes, I. L.; Rodrigues, T. Baccharis dracunculifolia, the main source of green propolis, exhibits potent antioxidant activity and prevents oxidant mitochondrial damage. Food. Chem. Toxicol, 2012, 50 (3-4), 1091-1097.

[94] Wassel, M. O.; Khattab, M. A. Antibacterial activity against Streptococcus mutans and inhibition of bacterial induced enamel demineralization of propolis, miswak, and chitosan nanoparticles based dental varnishes. J. $A d v$. Research, 2017, 8 (4), 387-392.

[95] Akyol, S.; Ozturk, G.; Ginis, Z.; Armutcu, F.; Yigitoglu, M. R; Akyol, O. In vivo and in vitro antineoplasic actions of caffeic acid phenetyl ester (CAPE): therapeutic perspectives. Nutritions. cancer, 2013, 65 (4), 515-526.

[96] Adomaviciute, E.; Stanys, S.; Zilius, M.; Juskaite, V.; Pavilonis, A.; Briedis, V. Formation and biopharmaceutical characterization of electrospun PVP mats with Propolis and silver nanoparticles for fast releasing wound dressing. Biomed. Research. Int, 2016.

[97] Ong, T. H. H.; Chitra, E.; Ramamurthy, S.; Siddalingam, R. P.; Yuen, K. H.; Ambu, S. P; Davamani, F. Chitosan-propolis nanoparticle formulation demonstrates anti-bacterial activity against Enterococcus faecalis biofilms. Plos One, 2017, 12 (3).

[98] Ong, T. H.; Chitra, E.; Ramamurth, S.; Ling, C. C. S.; Ambu, S. P.; Davamani, F. Cationic chitosan-propolis nanoparticles alter the zeta potential of $S$. epidermidis, inhibit biofilm formation by modulating gene expression and exhibit synergism with antibiotics. Plos One, 2019, 14 (2).
[99] Elbaz, N. M.; Khalil, I. A.; Rabon, A. A.; El-Sherbiny, I. M. Chitosan - Based nano in microparticle carriers for enhanced oral delivery and anticancer activity of Propolis. Int. J. Biol. Macromol, 2016, 92, 254- 269.

[100] Aman, R. M.; Abu-Hashim, I. I.; Meshali, M. M. Novel chitosan-based solid-lipid nanoparticles to enhance the bio-residence of the miraculous phytochemical “Apocynin”. Eur. J. Pharm. Sci, 2018, 124, 304-318.

[101] Lin, J. K.; Lin-Shiau, S. Y. Mechanisms of cancer chemoprevention by curcumin. Proc. Natl. Sci. Counc. Repub. China. B, 2001, 25 (2), 59-66.

[102] Marin, E.; Briceño, M. I.; Torres, A.; CaballeroGeorge, C. New curcumin-loaded chitosan nanocapsules: in vivo evaluation. Plant. Med, 2017, 83 (10), 877-883.

[103] Chuah, L H.; Roberts, C. J.; Billa, N.; Abdullah, S.; Rosli, R. Cellular uptake and anticancer effects of mucoadhesive curcumin-containing chitosan nanoparticles. Colloids Surf B Biointerfaces, 2014, 116, 228-236.

[104] Chuah, L. H.; Billa, N.; Roberts, C. J.; Burley, J. C.; Manickam, S. Curcumin-containing chitosan nanoparticles as a potential mucoadhesive delivery system to the colon. Pharm. Dev. Technol, 2013, 18 (3), 591-599.

[105] Jardim, K. V.; Joanitti, G. A.; Azevedo, R. B.; Parize, A. L. Physico-chemical characterization and cytotoxicity evaluation of curcumin loaded in chitosan/chondroitin sulfate nanoparticles. Mat. Sci. Eng: C, 2015, 56, 294-304.

[106] Udompornmongkol, P.; Chiang, B. H. Curcuminloaded polymeric nanoparticles for enhanced anti-colorectal cancer applications. J. Biomater. Appl, 2015, 30 (5), 537546.

[107] Yang, L.; Gao, S.; Asghar, S.; Liu, G.; Song, J.; Wang, X.; Ping, Q.; Zhang, C.; Xiao, Y. Hyaluronic acid/chitosan nanoparticles for delivery of curcuminoid and its in vitro evaluation in glioma cells. Int. J. Biol. Macromol, 2015, 72, 1391-1401.

[108] Zheng, Y.; Chen, Y.; Jin, L. W.; Ye, H. Y.; Liu, G. Cytotoxicity and genotoxicity in human embryonic kidney cells exposed to surface modify chitosan nanoparticles loaded with curcumin. AAPS PharmSciTech, 2016, 17 (6), 1347-1352.

[109] Khan, M. A.; Zafaryab, M.; Mehdi, S. H.; Ahmad, I.; Rizvi, M. M. Characterization and anti-proliferative activity of curcumin loaded chitosan nanoparticles in cervical cancer. Int. J. Biol. Macromol, 2016, 93, 242-253.

[110] Facchi, S. P.; Scariot, D. B.; Bueno, P. V. A.; Souza, P. R.; Figueiredo, L. C.; Follmann, H. D. M.; Nunes, C. S.; 
Monteiro, J. P.; Bonafé, E. G.; Nakamura, C. V.; Muniz, E. C.; Martins, A. F. Preparation and cytotoxicity of Nmodified chitosan nanoparticles applied in curcumin delivery. Int. J. Biomol. Macromol, 2016, 87, 237-245.

[111] Ammerman, N. C.; Beier-Sexton, M.; Azad, A. F. Growth and maintenance of Vero cell lines. Curr. Protoc. Microbiol, 2008.

[112] Abruzzo, A.; Zuccheri, G.; Belluti, F.; Provenzano, S.; Verardi, L.; Bigucci, F.; Cerchiara, T.; Luppi, B.; Calonghi, N. Chitosan nanoparticles for lipophilic anticancer drug delivery: development, characterization and in vitro studies on HT29 cancer cells. Colloids. Surf B. Biointerfaces, 2016, $145,362-372$.

[113] Rizzi, M.; Tonello, S.; Estevão, B. M.; Gianotti, E.; Marchese, L.; Reno, F. Verteporfin based silica nanoparticle for in vitro selective inhibition of human highly invasive melanoma cell proliferation. J. Photochem. Photobiol B, 2017, 167, 1-6.

[114] Duse, L.; Baghdan, E.; Pinnapireddy, S. R.; Engelhardt, K. H.; Jedelská, J.; Schaefer, J.; Quendt, P.; Bakowsky, U. Preparation and characterization of curcumin loaded chitosan nanoparticles for photodynamic therapy. IPSS Apl. Mat. Sci, 2017, 215 (15), 1-5.

[115] Hashemian, M.; Anissian, D.; Ghasemi-Kasman, M.; Akbari, A.; Khalili-Fomeshi, M.; Ghasemi, S.; Ahmadi, F.; Moghadamnia, A. A.; Ebrahimpour, A. Curcumin-loaded chitosan-alginate-STPP nanoparticles ameliorate memory deficits and reduce glial activation in pentylenetetrazolinduced kindling model of epilepsy. Prog. Neurpsychopharmacol. Biol. Psychiatry, 2017, 79, 462-471.

[116] Yadav, P.; Bandyopadhyay, A.; Chakraborty, A.; Sarkar, K. Enhancement of anticancer activity and drug delivery of chitosan-curcumin nanoparticle via molecular docking and simulation analysis. Carbohydr. Polym, 2018, 182, 188-198.

[117] Mazzarino, L.; Loch-Neckel, G.; Budniak-Ldos, S.; Mazzucco, S.; Santos-Silva, M. C.; Borsali, R.; LemosSenna, E. Curcumin-loaded chitosan-coated nanoparticles as a new approach for the local treatment of oral cavity cancer. J. Nanosci. Nanotechnol, 2015, 15 (1), 781-791.

[118] Loch-Neckel, G.; Santos-Budniak, L.; Mazzarino, L.; Jacques, A. V.; Moccelin, B.; Santos-Silva, M. C.; LemosSenna, E. Orally administered chitosan-coated polycaprolactone nanoparticles containing curcumin attenuate metastatic melanoma in the lungs. J. Pharm. Sci, 2015, 104 (10), 3524-3534.

[119] Suresh, K.; Nangia, A. Curcumin: pharmaceutical solids as a platform to improve solubility and bioavailability. Crystengcomm, 2018, 20 (24), 3277-3296.
[120] Vijayakurup, V.; Thulasidasan, A. T.; Shankar-G, M.; Retnakumari, A. P.; Nandan, C. D.; Somaraj, J.; Antony, J.; Alex, V. V.; Vinod, B. S.; Liju, V. B.; Sundaram, S.; Kumar, G. S. V.; Anto, R. J. Chitosan encapsulation enhances the bioavailability and tissue retention of curcumin and improves its efficacy in preventing $\mathrm{B}[\mathrm{a}] \mathrm{P}$-induced lung carcinogenesis. AACR Cancer Prevention Research, 2019, 135 .

[121] Hasan, M.; Elkhoury, K.; Kahn, C. J. F.; ArabTehrany, E.; Linder, M. Preparation, Characterization, and release kinetics of chitosan-coated nanoliposomes encapsulating curcumin in simulated environments. Molecules, 2019, 24 (10), 2023-2037.

[122] Elbialy, N. S; Elfatah, E. A.; Khalil, W. A. Preparation and characterization of curcumin loaded dextrin sulfatechitosan nanoparticles for promoting curcumin anticancer activity. J. Adv Physics, 2019, 16 (1), 185-195.

[123] Frieri, M.; Kumar, K.; Boutin, A. Antibiotic resistance. J. Infect. Public. Health, 2017, 10 (4), 369-378.

[124] Aziz, N.; Pandey, R.; Barman, I.; Prasad, R. Leveraging the attributes of Mucor hiemalis-derived silver nanoparticles for a synergistic broad-spectrum antimicrobial platform. Front. Microbiol, 2016, 7.

[125] Shlar, I.; Droby, S.; Rodov, V. Modes of antibacterial action of curcumin under dark and light conditions: A toxicoproteomics approach. J. Proteomics, 2017, 160, 8-20.

[126] Yun, D. G.; Lee, D. G. Antibacterial activity of curcumin via apoptosis-like response in Escherichia coli. Applied Microbiol. Biotech, 2016, 100 (12), 5505-5514.

[127] Pang, Z.; Raudonis, R.; Glick, B. R.; Lin, T. J.; Cheng, Z. Antibiotic resistance in Pseudomonas aeruginosa: mechanisms and alternative therapeutic strategies. Biotech. Adv, 2019, 37 (1), 177-192.

[128] Neyestani, Z.; Ebrahimi, S. A.; Ghazaghi, A.; Jalili, A.; Sahebkar, A.; Rahimi, H. R.; Review of anti-bacterial activities of curcumin against Pseudomonas aeruginosa. Critical Reviews In Eukaryotic Gene Expression, 2019, 29 (5), 377-385.

[129] Samrot, A.; Burman, U.; Philip, S. A.; Shobana, N.; Chandrasekaran, K. Synthesis of curcumin loaded polymeric nanoparticles from crab shell derived chitosan for drug delivery. Inf. Med. Unlocked, 2018, 10, 159-182.

[130] Niranjan R.; Kaushik, M.; Prakash, J.; Venkataprasanna, K. S.; Christy, A.; Pannerselvam, B.; Venkatasubbu, G. D. Enhanced wound healing by PVA/Chitosan/Curcumin patches: In vitro and in vivo 
study. Colloids And Surfaces B: Biointerfaces, 2019, 182, 11-19.

[131] Kumar, D.; Raj, V.; Verma, A.; Kumar, P.; Pandey, J. Novel binary grafted chitosan nanocarrier for sustained release of curcumin. Int. J. Biol. Macromol, 2019, 131, 184191.

[132] Vishwakarma, A.; Sriram, P.; Preetha, S. P.; Tirumurugaan, K. G.; Nagarajan, K.; Pandian, K. Synthesis and characterization of Chitosan / TPP encapsulated curcumin nanoparticles and its antibacterial efficacy against colon bacteria. Int. J. Chem. Studies, 2019, 7 (3), 602-606.

[133] Agel, M. R.; Baghdan, E.; Pinnapireddy, S. R.; Lehmann, J.; Schäfer, J.; Bakowsky, U. Curcumin loaded nanoparticles as efficient photoactive formulations against gram-positive and gram-negative bacteria. Colloids Surf B Biointerfaces, 2019, 178, 460-468.

[134] Barbinta-Patrascu, M. E.; Badea, N.; Pirvu, C.; Bacalum, M.; Ungureanu, C.; Nadejde, P. L.; Ion, C.; Rau, I. Multifunctional soft hydrid bio-platforms based on nanosilver and natural compounds. Mater. Sci. Eng C. Mater. Biol. Appl, 2016, 69, 922-932.

[135] Rao-Kummara, M.; Kumar, A.; Soo, H. S. Development of antibacterial paper coated with sodium hyaluronate stabilized curcumin-Ag nanohybrid and chitosan via polyelectrolyte complexation for medical applications. Mater. Res. Express, 2017, 4, 115401.

[136] Yu, H.; Tran, T. T.; Teo, J.; Hadinoto, K. Dry powder aerosols of curcumin-chitosan nanoparticle complex prepared by spray freeze drying and their antimicrobial efficacy against common respiratory bacterial pathogens. Colloids and Surfaces A: physicochemical and Engineering Aspects, 2016, 504, 34-42.

[137] Ferfera-Harrar, H.; Berdous, D.; Benhalima, T. Hydrogel nanocomposites based on chitosan-gpolyacrylamide and silver nanoparticles synthesized using Curcuma longa for antibacterial applications. Polym. Bull, 2018, 75, 2819-2846.

[138] Maghsoudi, A.; Yazdian, F.; Shahmoradi, S.; Ghaderi, L.; Hemati, M.; Amoabediny, G. Curcumin-loaded polysaccharide nanoparticles: optimization and anticariogenic activity against Streptococcus mutans. Mat. Sci. Eng, 2017, 75, 1259-1267.

[139] Akram, M.; Hussain, R. Nanohydrogels: History, development, and applications in drug delivery. Nanocel. Nanohydrogel. Matrices, 2017, 297-330.

[140] El-Banna, F. S.; Mahfouz, M. E.; Leporatti, S.; ElKemary, M.; Hanafy, N. A. N. Chitosan as a natural copolymer with unique properties for the development of hydrogels. Applied Sciences, 2019, 9 (11), 2193-2204.

[141] Liu, X.; You, L.; Tarafder, S.; Zou, L.; Fang, Z.; Chen, J.; Lee, C. H.; Zhang, Q. Curcumin-releasing chitosan/aloe membrane for skin regeneration. Chem. Eng. J, 2019, 359, 1111-1119.

[142] Rezaii, M.; Oryan, S.; Javeri, A. Curcumin nanoparticles incorporated collagen-chitosan scaffold promotes cutaneous wound healing through regulation of TGF- $\beta 1 /$ Smad7 gene expression. Mat Sci Eng: C, 2019, 98, 347-357.

[143] Cheng, Y. H.; Ko, Y. C.; Chang, Y. F.; Huang, S. H.; Liu, C. J. Thermosensitive chitosan-gelatin-based hydrogel containing curcumin-loaded nanoparticles and latanoprost as a dual-drug delivery system for glaucoma treatment. Experimental Eye Research, 2019, 179, 179-187.

[144] Thomas, L.; Zakir, F.; Mirza, M.A.; Anwer, M. K., Ahmad, F. J.; Igbal, Z. Development of curcumin loaded chitosan polymer based nanoemulsion gel: in vitro, ex vivo evaluation and in vivo wound healing studies. Int. J. Biol. Macromol, 2017, 101, 569-579.

[145] Esfandiarpour-Boroujeni, S.; Bagheri-Khoulenjani, S.; Mirzaded, H.; Amanpour, S. Fabrication and study of curcumin loaded nanoparticles based on folate-chitosan for breast cancer therapy application. Carbohydr. Polym, 2017, $168,14-21$.

[146] Ahmad, M.; Taweel, G. M. A.; Hidayathulla, S. Nanocomposites chitosan-curcumin synergistically inhibits the oxidative stress induced by toxic metal cadmium. Int. J. Biol. Macromol, 2018, 108, 591-597.

[147] Khan, M. A.; Zafaryab, M.; Mehdi, S. H.; Ahmad, I.; Rizvi, M. M. A. Physicohemical characterization of curcumin loaded chitosan nanoparticles: implication in cervical cancer. Anticancer. Agents. Med. Chem, 2018, 18 (8), 1131-1137.

[148] Mahattanadul, S.; Mustafa, M. W.; Kuadkaew, S.; Pattharachayakul, S.; Ungphaiboon, S.; Sawanyawisuth, K. Oral ulcer healing and anti-candida efficacy of an alcoholfree chitosan-curcumin mouthwash. Eur. Rev. Med. Pharmacol. Sci, 2018, 22 (20), 7020-7023.

[149] Nguyen, M. H.; Lee, S. E.; Tran, T. T.; Bui, C. B.; Nguyen, T. H.; Vu, N. B.; Tran, T. T.; Nguyen, T. H.; Nguyen, T. T.; Hadinoto, K. A simple strategy to enhance the in vivo wound-healing activity of curcumin in the form of self-assembled nanoparticle complex of curcumin and oligochitosan. Mater. Sci. Eng. C Mater. Biol. Appl, 2019, 98, 54-64. 
[150] Nair, R. S.; Morris, A.; Billa, N.; Leong, C. O. An evaluation of curcumin-encapsulated chitosan nanoparticles for transdermal delivery. AAPS PharmSciTech, 2019, 20 (2), 69.

[151] Jardim, K. V.; Siqueira, J. L. N.; Báo, S. n.; Sousa, M. H.; Parize, A. L. The role of the lecithin addition in the properties and cytotoxic activity of chitosan and chondroitin sulfate nanoparticles containing curcumin. Carbohydrate Polymers, 2020, 227, 1-10. 